\title{
Laboratory Performance Evaluation in Terms of Water Analysis Through an External Quality Control
}

\author{
Lucienne V. Rakotozafy ${ }^{1}$, Hanitriniaina Ramaherison' ${ }^{1}$, Njaka N. Andriamahenina ${ }^{1}$, \\ Elise O. Rasoazanany ${ }^{1}$, Herinirina N. $\operatorname{Ravoson}^{1}$, Raoelina Andriambololona ${ }^{2}$ \\ ${ }^{1}$ X-Ray Fluorescence and Environment Department, Institut National des Sciences et Techniques Nucléaires, Madagascar \\ (INSTN-Madagascar), Antananarivo, Madagascar \\ ${ }^{2}$ Theoritical Physics Department, INSTN-Madagascar, Antananarivo, Madagascar
}

\section{Email addresses:}

lvrakoto@gmail.com (L. V. Rakotozafy), jacquelineraoelina@hotmail.com (R. Andriambololona)

\section{To cite this article:}

Lucienne V. Rakotozafy, Hanitriniaina Ramaherison, Njaka N. Andriamahenina, Elise O. Rasoazanany, Herinirina N. Ravoson, Raoelina Andriambololona. Laboratory Performance Evaluation in Terms of Water Analysis Through an External Quality Control. Science Journal of Analytical Chemistry. Vol. 3, No. 2, 2015, pp. 22-29. doi: 10.11648/j.sjac.20150302.12

\begin{abstract}
This paper presents the results of participation of Institut National des Sciences et Techniques Nucléaires-Madagascar (INSTN-Madagascar) in interlaboratory comparisons organized annually, since 2007, by Southern African Development Community WaterLab Association. The following text describes an overview of the utility of provided proficiency testing programs used as an external quality control with respect to proving consistency and reliability of water analysis at INSTN-Madagascar. Total reflection X-Ray Fluorescence spectrometry and Atomic Absorption Spectrometry are both used to measure the following trace metals: $\mathrm{Al}, \mathrm{Cr}, \mathrm{Mn}, \mathrm{Fe}, \mathrm{Ni}, \mathrm{Co}, \mathrm{Cu}, \mathrm{Zn}, \mathrm{As}, \mathrm{Cd}, \mathrm{Pb}$. The analysis of minor and major ions such as $\mathrm{Cl}^{-}, \mathrm{F}^{-}, \mathrm{NO}_{3}{ }^{-}, \mathrm{SO}_{4}{ }^{2-}, \mathrm{PO}_{4}{ }^{3-}, \mathrm{K}^{+}, \mathrm{Na}^{+}, \mathrm{Ca}^{2+}, \mathrm{Mg}^{2+}$ are conducted by using Ion Chromatography. To illustrate, graphical distributions of z-scores calculated from the results of water measurements are presented. During the consecutive proficiency testing rounds, INSTN-Madagascar has succeeded to have more than $80 \%$ of the values within tolerance limits on 2007,2008 , 2010, 2011, 2012 and 2013. This paper shows some of the considerations for participating to proficiency testing exercises which could be used to obtain certain value from the schemes.
\end{abstract}

Keywords: Total Reflection X-Ray Fluorescence, Atomic Absorption Spectrometry, Ion Chromatography, Proficiency Testing, Z-Score

\section{Introduction}

The present paper is focused on the results of interlaboratory comparisons organized annually, from 2007 to 2013, by Southern African Development Community (SADC) Waterlab in which INSTN-Madagascar takes part. For this purpose, the proficiency testing (PT) provider establishes performance scores by comparison of the laboratories results to the assigned value by transforming the qualitative results into quantifiable data based on predetermined criteria. Graphical plots of performance scores from round to round are presented.

The aim of this study is to assess and to demonstrate the performance of X-Ray Fluorescence and Environment (XRFE) Department in INSTN-Madagascar for some chemical elements in water through interlaboratory comparisons and to monitor the laboratory's continuing performance.
With respect to meeting the objectives described above, the laboratory staff within XRFE department would assess and demonstrate the consistency and reliability of the data they are producing, gain confidence in their abilities, improve or at least maintain a level of competence comparable with the previous rounds, detect any difficulties they may meet with measurements and identify training needs, provide additional confidence to customers.

\section{Experimental Procedure}

\subsection{Testing Samples Specification}

The chemistry PT round involved the distribution of six testing samples which were prepared as described in Table 1. 


\subsection{Distribution of Samples and Return Date for the Results}

The samples were distributed to the local coordinators in each participating country provided that registration forms were submitted and payment had been received.

The participating laboratories have to submit their results onto a supplied result form to the PT scheme providers before or on the return date. Results received after the specified periods are not included in the final report.

Table 1. Characteristics of the testing samples information

\begin{tabular}{|c|c|c|c|}
\hline \multicolumn{2}{|c|}{ Samples \#1, \#2 and \#3 } & \multicolumn{2}{|c|}{ Samples $\# 4, \# 5$ and $\# 6$} \\
\hline Analytes & Range (mg/L) & Analytes & Range (mg/L) \\
\hline $\begin{array}{l}\text { Sulphate as } \\
\mathrm{SO}_{4}{ }^{2-} \text { in } \mathrm{mg} / \mathrm{L}\end{array}$ & $0-100$ & $\begin{array}{l}\text { Calcium as } \mathrm{Ca}^{2+} \\
\text { in } \mathrm{mg} / \mathrm{L}\end{array}$ & $0-100$ \\
\hline $\begin{array}{l}\text { Chloride as } \mathrm{Cl}^{-} \\
\text {in } \mathrm{mg} / \mathrm{L}\end{array}$ & $0-100$ & $\begin{array}{l}\text { Magnesium as } \\
\mathrm{Mg}^{+} \text {in } \mathrm{mg} / \mathrm{L}\end{array}$ & $0-50$ \\
\hline $\begin{array}{l}\text { Nitrate as } \mathrm{NO}_{3}{ }^{-} \\
\text {in } \mathrm{mg} / \mathrm{L}\end{array}$ & $0-50$ & $\begin{array}{l}\text { Sodium as } \mathrm{Na}^{+} \text {in } \\
\mathrm{mg} / \mathrm{L}\end{array}$ & $0-100$ \\
\hline $\begin{array}{l}\text { Fluoride as } \mathrm{F}^{-} \\
\text {in } \mathrm{mg} / \mathrm{L}\end{array}$ & $0-10$ & $\begin{array}{l}\text { Potassium as } \mathrm{K}^{+} \\
\text {in } \mathrm{mg} / \mathrm{L}\end{array}$ & $0-50$ \\
\hline \multirow[t]{10}{*}{$\begin{array}{l}\text { Phosphate as } \\
\mathrm{PO}_{4}{ }^{3-} \text { in } \mathrm{mg} / \mathrm{L}\end{array}$} & $0-50$ & $\begin{array}{l}\text { Iron as Fe in } \\
\mathrm{mg} / \mathrm{L}\end{array}$ & $0-3$ \\
\hline & & $\begin{array}{l}\text { Manganese as } \\
\mathrm{Mn} \text { in } \mathrm{mg} / \mathrm{L}\end{array}$ & $0-3$ \\
\hline & & $\begin{array}{l}\text { Aluminium as } \mathrm{Al} \\
\text { in } \mathrm{mg} / \mathrm{L}\end{array}$ & $0-3$ \\
\hline & & $\begin{array}{l}\mathrm{Lead} \text { as } \mathrm{Pb} \text { in } \\
\mathrm{mg} / \mathrm{L}\end{array}$ & $0-3$ \\
\hline & & $\begin{array}{l}\mathrm{Zinc} \text { as } \mathrm{Zn} \text { in } \\
\mathrm{mg} / \mathrm{L}\end{array}$ & $0-3$ \\
\hline & & $\begin{array}{l}\text { Chromium as } \mathrm{Cr} \\
\text { in } \mathrm{mg} / \mathrm{L}\end{array}$ & $0-3$ \\
\hline & & $\begin{array}{l}\text { Nickel as } \mathrm{Ni} \text { in } \\
\mathrm{mg} / \mathrm{L}\end{array}$ & $0-3$ \\
\hline & & $\begin{array}{l}\text { Arsenic as As in } \\
\mathrm{mg} / \mathrm{L}\end{array}$ & $0-3$ \\
\hline & & $\begin{array}{l}\text { Cadmium as } \mathrm{Cd} \\
\text { in } \mathrm{mg} / \mathrm{L}\end{array}$ & $0-3$ \\
\hline & & $\begin{array}{l}\text { Cobalt as Co in } \\
\mathrm{mg} / \mathrm{L}\end{array}$ & $0-3$ \\
\hline
\end{tabular}

\subsection{Exercise Report}

An electronic evaluation report is then supplied to all participants in time. The information that is found in this document is confidential to the PT provider and to the participating laboratory of which a labcode is attributed.

\subsection{Analytical Measurements}

\subsubsection{Analytical Methods}

Participants have been invited to conduct the analysis according to their routine procedure.

As for INSTN-Madagascar, testing samples were measured by using:

- Ion Chromatography (IC) DX-120 for Sulphate, Chloride, Fluoride, Nitrate, Phosphate, Calcium, Magnesium, Sodium, Potassium which are classified as major and minor ions [1].

- Total reflection X-Ray Fluorescence (TXRF) for the following trace metals: Manganese, Arsenic, Cobalt, Chromium, Copper, Nickel, Lead and Zinc [2], [3].
- Flame and Graphite Furnace Atomic Absorption Spectrometer (AAS) for the following trace metals: Aluminium, Cadmium, Iron, Cobalt, Chromium, Copper, Nickel, Lead and Zinc. Measurements were performed using VARIAN equipment with an AA240FS flame and an AA240Z graphite furnace [4].

\subsubsection{Sample Preparation}

The sample preparation depends on the analytical methods used:

- for IC and AAS, there is no preparation

- as for TXRF, $5 \mathrm{mg} / \mathrm{L}$ of yttrium used as internal standard are added to the sample solution as described in [5].

\subsubsection{Calibration}

By dilution with deionized water, calibration standard solutions are daily prepared from a working standard solution containing all the analytes mentioned in Table 1 .

As for the working standard solutions, ions and trace metals are prepared separately and their concentrations are chosen to be equal to the maximum value described in column "range" in Table 1. As an example, ions working standard solution contain approximately $100 \mathrm{mg} / \mathrm{L}$ of sulphates, $50 \mathrm{mg} / \mathrm{L}$ of nitrates, $50 \mathrm{mg} / \mathrm{L}$ of magnesium and trace metals working standard solution has $3 \mathrm{mg} / \mathrm{L}$ of iron, $3 \mathrm{mg} / \mathrm{L}$ of lead. All of them are prepared from $1000 \mathrm{mg} / \mathrm{L}$ of stock solutions.

Six solutions are prepared by dilution from each category. The dilution factors are chosen as follows: 1, 5, 8, 10, 16, 20. Calibration curves are plotted on six points for each analyte in a range as defined in Table 1.

\section{Results and Discussion}

\subsection{Internal Quality Control by Using Reference Materials}

The accuracy of the instrumental methods and analytical procedures are checked by using the following Reference Materials (RMs) solutions:

- mixture of VKI-16-4-0199 and VKI-16-5-0199 for $\mathrm{Ca}^{2+}$, $\mathrm{Mg}^{+}, \mathrm{Na}^{+}, \mathrm{K}^{+}, \mathrm{Cl}^{-}, \mathrm{F}^{-}$and $\mathrm{SO}_{4}{ }^{2-}$

- VKI-5-4-304 for $\mathrm{NO}_{3}{ }^{-}$and $\mathrm{PO}_{4}{ }^{3-}$

- ICP Multi-Element Standard BDH ARISTAR for Al, Ba, $\mathrm{Cd}, \mathrm{Cr}, \mathrm{Co}, \mathrm{Cu}, \mathrm{Fe}, \mathrm{Pb}, \mathrm{Mn}, \mathrm{Ni}, \mathrm{Sr}$ and $\mathrm{Zn}$.

Tables 2 and 3 show the measurement results of the above mentioned RMs at the time of 2013 round. The tables report the mean concentration and standard deviation values of 4 replicates.

Table 2. Analysis of VKI-5-4-304 and the mixture of VKI-16-4-0199 and VKI-16-5-0199.

\begin{tabular}{lll}
\hline Analytes & Assigned values $(\mathbf{m g} / \mathbf{L})$ & Laboratory results $(\mathbf{m g} / \mathbf{L}) \mathbf{I C}$ \\
\hline $\mathrm{Ca}^{2+}$ & 5.46 & $6.5 \pm 0.6$ \\
$\mathrm{~K}^{+}$ & 5.46 & $6.0 \pm 1.0$ \\
$\mathrm{Mg}^{+}$ & 28.54 & $27.1 \pm 1.0$ \\
$\mathrm{Na}^{+}$ & 54.53 & $53.3 \pm 3.2$ \\
$\mathrm{Cl}^{-}$ & 66.7 & $67.1 \pm 2.8$ \\
$\mathrm{~F}^{-}$ & 1.12 & $1.1 \pm 0.03$ \\
$\mathrm{NO}_{3}{ }^{-}$ & 5.47 & $6.4 \pm 0.5$ \\
$\mathrm{PO}_{4}{ }^{3-}$ & 0.55 & $0.5 \pm 0.07$ \\
$\mathrm{SO}_{4}{ }^{2-}$ & 65.97 & $66.5 \pm 1.8$ \\
\hline
\end{tabular}


Table 3. Analysis of ICP Multi-Element Standard BDHARISTAR.

\begin{tabular}{llll}
\hline \multirow{2}{*}{ Analytes } & \multirow{2}{*}{ Assigned values $(\mathbf{m g} / \mathbf{L})$} & \multicolumn{2}{c}{ Laboratory results(mg/L) } \\
\cline { 3 - 4 } & & TXRF & AAS \\
\hline $\mathrm{Al}$ & 100 & $5.2 \pm 0.8$ & $102.4 \pm 2.7$ \\
$\mathrm{Ba}$ & 5 & & $21.3 \pm 1.4$ \\
$\mathrm{Cd}$ & 20 & $19.6 \pm 1.0$ & $19.6 \pm 0.8$ \\
$\mathrm{Co}$ & 20 & $25.2 \pm 2.0$ & $26.7 \pm 2.4$ \\
$\mathrm{Cr}$ & 25 & $20.9 \pm 1.9$ & $19.5 \pm 0.6$ \\
$\mathrm{Cu}$ & 20 & & $15.7 \pm 1.1$ \\
$\mathrm{Fe}$ & 15 & $4.9 \pm 0.5$ & \\
$\mathrm{Mn}$ & 5 & $49.1 \pm 4.7$ & $41.4 \pm 2.4$ \\
$\mathrm{Ni}$ & 50 & $202 \pm 11$ & $192.7 \pm 8.0$ \\
$\mathrm{~Pb}$ & 200 & $0.98 \pm 0.02$ & \\
$\mathrm{Sr}$ & 1 & $21.1 \pm 4.2$ & $19.8 \pm 1.3$ \\
$\mathrm{Zn}$ & 20 & \multicolumn{2}{c}{} \\
\hline
\end{tabular}

Quality assessment statistics are presented graphically through control charts for ease of interpretation. The measurements of RMs are graphed on this chart as the recovery rate noted $\% \mathrm{R}$ vs analytes. These charts can be used to present both bias and precision data.

The analytical recovery rate $\% \mathrm{R}$ is expressed as follows [6]:

$$
\% R=100 \frac{V_{\text {lab }}}{V_{\text {assigned }}}
$$

where: $V_{l a b}$ is the value reported by the laboratory and $V_{\text {assigned }}$ is the assigned value.

The range of the acceptable criteria for recovery is laid down based on the concentration of the analyte. The target recovery ranges from $80 \%$ to $110 \%$ for analyte concentrations from 0.1 to $100 \mathrm{mg} / \mathrm{L} \mathrm{[7].}$

The calculation of $\% \mathrm{R}$, as defined in (1) for each analyte allows to graph the charts in Fig. 1 and Fig. 2.
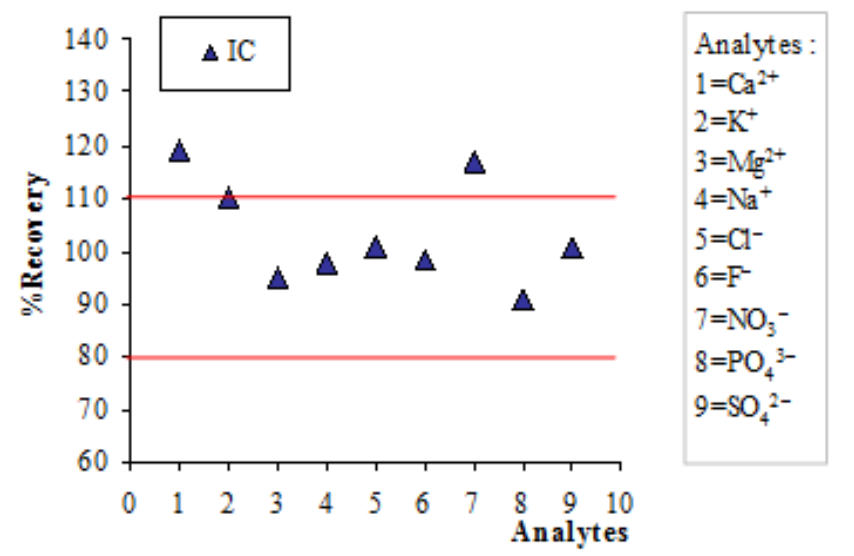

Fig. 1. Distribution of recovery rate for minor and major ions in the analyzed $R M s$.

Now, figures 1 and 2 show that recoveries within $83 \%$ to $119 \%$ are obtained for all analytes as far as the three analytical methods are concerned. $\mathrm{Ca}^{2+}$ and $\mathrm{NO}_{3}^{-}$are slightly overestimated with respectively recovery values $119 \%$ and $117 \%$. The comparison of TXRF results with those obtained by AAS measurements are in good agreement for all analytes.

According to the above mentioned criteria, the agreement between the assigned values and the laboratory values is generally good.

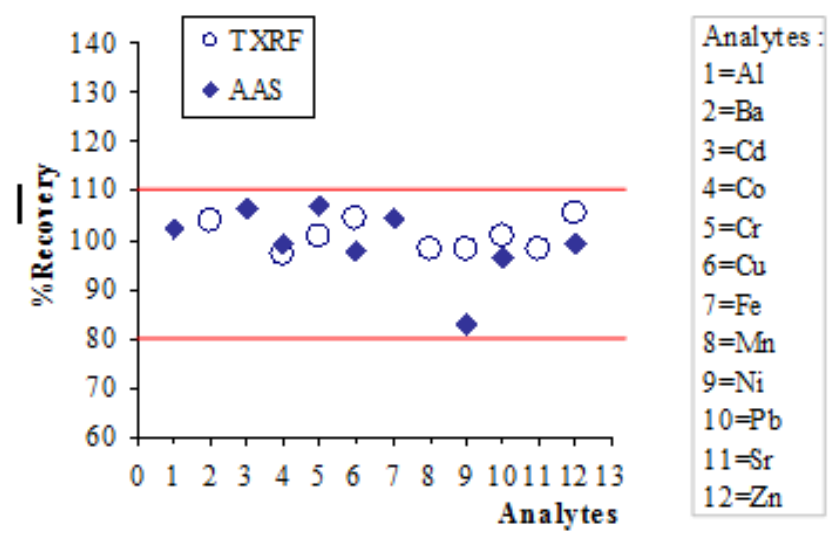

Fig. 2. Distribution of recovery rate for trace metals in the analyzed RMS.

In case the recovery differs significantly from $100 \%$, the PT result values are corrected by calculation for recovery according to the following formula:

$$
V_{l a b}^{r}=100 \frac{V_{l a b}^{m}}{\% R}
$$

where: $V_{l a b}^{r}$ is the value reported by the individual laboratory, $V_{l a b}^{m}$ is the value measured by the individual laboratory and $\% \mathrm{R}$ is the recovery.

\subsection{Evaluation Report}

The evaluation report within the SADC PT provider for water testing laboratories was supplied with a strict confidentiality. The results are grouped versus analytes/laboratories and compared according to z-score values.

The formula for the z-score is [8]:

$$
Z=\frac{V_{\text {lab }}-V_{\text {assigned }}}{S_{d}}
$$

where: $V_{l a b}$ is the value reported by the individual laboratory, $V_{\text {assigned }}$ is the assigned value and $S_{d}$ is the standard deviation for proficiency assessment.

According to $\mathrm{Ph}$. Quevauviller, E. A. Maier [9], the following judgment is made:

Results leading to $|z| \leq 2$ are satisfactory

Results leading to $2<|z| \leq 3$ are questionable all other results $|z|>3$ are unsatisfactory

A laboratory is considered successful in analysing an analyte if two or more z-scores for the analyte are satisfactory.

Table 4 illustrates an example of the performance evaluation result carried out by SADC Waterlab. 
Table 4. Example of the performance evaluation result reported by SADC Waterlab.

\begin{tabular}{|c|c|c|c|c|c|c|c|}
\hline Analyte & Sample \# & $\begin{array}{l}\text { Assigned value in } \\
\mathrm{mg} / \mathrm{L}\end{array}$ & $\begin{array}{l}\text { Laboratory result } \\
\text { in } \mathrm{mg} / \mathrm{L}\end{array}$ & $\begin{array}{l}\text { Standard for assessment } \\
\text { in } \mathrm{mg} / \mathrm{L}\end{array}$ & z-score & Assessment & Rating \\
\hline \multirow{3}{*}{$\mathrm{Mn}$} & 4 & 0.42 & 0.43 & 0.05 & 0.19 & + & \multirow{3}{*}{ Acceptable } \\
\hline & 5 & 1.06 & 0.98 & 0.13 & -0.60 & + & \\
\hline & 6 & 2.10 & 2.08 & 0.23 & -0.09 & + & \\
\hline \multirow{3}{*}{$\mathrm{Cu}$} & 4 & 0.95 & 0.94 & 0.08 & -0.13 & + & \multirow{3}{*}{ Acceptable } \\
\hline & 5 & 1.90 & 1.78 & 0.14 & -0.89 & + & \\
\hline & 6 & 3.15 & 2.06 & 0.23 & -4.72 & - & \\
\hline \multirow{3}{*}{$\mathrm{Fe}$} & 4 & 0.88 & 0.56 & 0.10 & -3.25 & - & \multirow{3}{*}{ Unacceptable } \\
\hline & 5 & 1.62 & 1.16 & 0.19 & -2.38 & - & \\
\hline & 6 & 2.52 & 1.08 & 0.30 & -4.76 & - & \\
\hline \multirow{3}{*}{$\mathrm{NO}_{3}^{-}$} & 1 & 9.96 & 16.02 & 1.50 & 4.05 & - & \multirow{3}{*}{ Unacceptable } \\
\hline & 2 & 34.46 & 55.71 & 5.17 & 4.11 & - & \\
\hline & 3 & 14.82 & 17.82 & 2.22 & 1.35 & + & \\
\hline
\end{tabular}

In fact, the $\mathrm{z}$-score is the one of the common statistics used for the evaluation of performance; in other words the z-score is an indicator to quantify the analytical performance of participating laboratory.

Taking into account the evaluation of consecutive PT rounds results, a graphical plot of performance scores by using the z-scores from round to round is drawn up, in order to identify potential problems related to imprecision and human errors.

Figures 3.1.a. until 3.7.b. group the graphical distribution of $\mathrm{z}$-scores for measured analytes respectively in terms of trace metals and ions and separately on 2007, 2008, 2009, 2010, 2011, 2012 and 2013 PT rounds. The main results are summarized as follows.

\subsubsection{Trace Metals}

During the consecutive PT rounds, measurements were conducted by using TXRF and AAS techniques with minimum sample preparation.

2007 PT round: figure 3.1.a shows that 7 out of 24 results were "out of control". Among the 8 tested elements, the results which are got from $\mathrm{Fe}$ in the three testing samples are found to be out of control.

Regarding the results from the 2008 to 2013 PT rounds, the measurements of water samples look good. The TXRF and AAS analytical methods perform well for the analysis of water samples as for $\mathrm{Fe}, \mathrm{Mn}, \mathrm{Al}, \mathrm{Pb}, \mathrm{Cu}, \mathrm{Zn}, \mathrm{Cr}, \mathrm{Ni}, \mathrm{As}, \mathrm{Cd}$ and $\mathrm{Co}$.

\subsubsection{Minor and Major Ions}

During the consecutives PT rounds, measurements were conducted by using IC technique with minimum sample preparation.

During 2007- 2008 - 2010 - 2012 and 2013 PT rounds, the measurements of water samples look good because we have only 1 outlier out of 27 results in 2012 then 4 outliers out of 27 results in 2013. These outliers come from $\mathrm{Na}^{+}$in sample \#1 then from $\mathrm{PO}_{4}{ }^{3-}$ in sample $\# 1, \mathrm{Ca}^{2+}$ in sample $\# 2, \mathrm{Cl}^{-}$and $\mathrm{NO}_{3}{ }^{-}$ in sample \#3.

2009 PT round: figure 3.3.b shows that 15 out of 27 results were outliers. The results of anions in samples \#1 and \#2 are among these outliers with an overestimation.

2011 PT round: the situation was mismanaged during this round as far as ions measurements are concerned; 12 out of 27 results are "out of control" (figure 3.5.b). Even so, the IC technique determines positively biased values for anion parameters.

It can be concluded that the performance of the XRF laboratory in INSTN-Madagascar is better for the quantification of trace metals in water samples comparing to ion parameters.

After evaluation of the cause of the nonconforming ion chromatography results, the following precautions are taken:

- avoid to change the eluents during a series of measurements;

- do not use outdated RMs, standard reference materials (SRMs) and certified reference materials (CRMs)

- use a daily fresh preparation (eluents, SRMs, CRMs);

- check from time to time if there is no liquid leak inside the analytical apparatus.

In all figures 3 , the horizontal lines show the admissible levels of $\mathrm{z}$-score, $|\mathrm{z}|=3$ - solid lines and $|\mathrm{z}|=2$ - dashed lines.

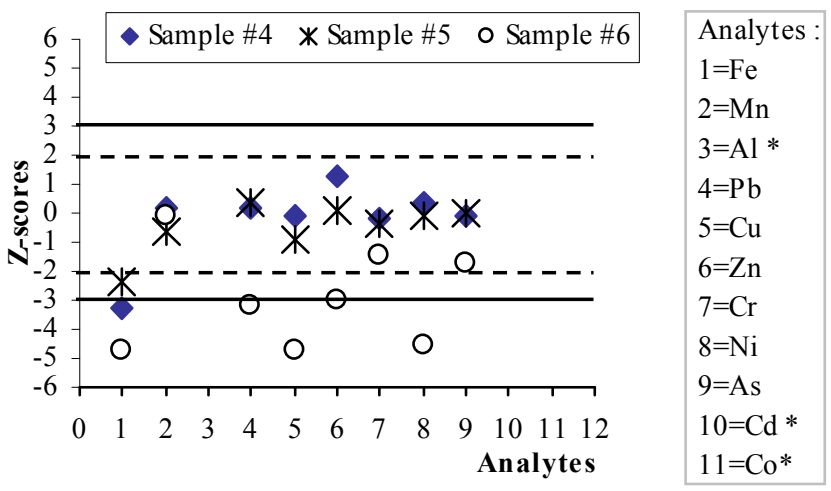

Fig. 3.1.a. Trace metals 2007.

*Remarks

- Cobalt is not plotted in graph "Trace metals 2007" as the testing samples in 2007 round did not contain cobalt.

- The AAS equipment was only installed on November 2008; while, on the other hand, TXRF module could not ensure the detection of $\mathrm{Al}$ and $\mathrm{Cd}$. 


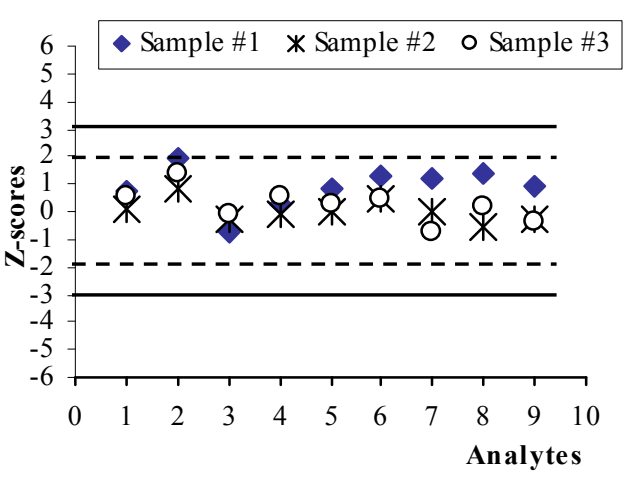

Fig. 3.1.b. Minor and major ions 2007.

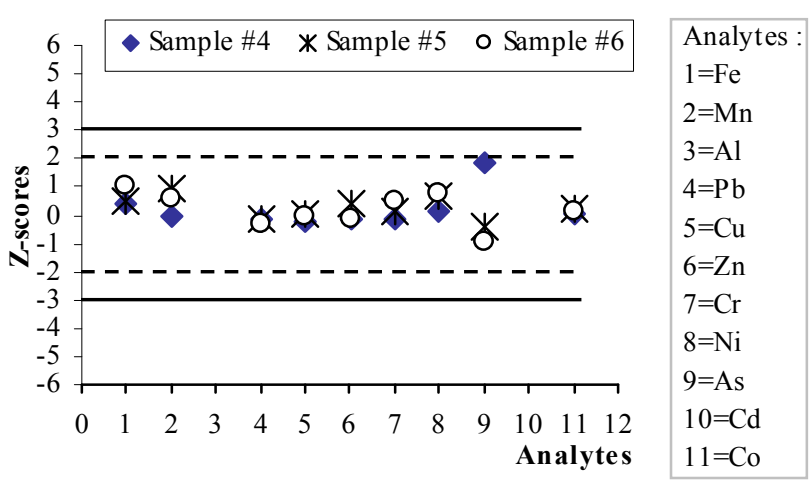

Fig. 3.2.a. Trace metals 2008.

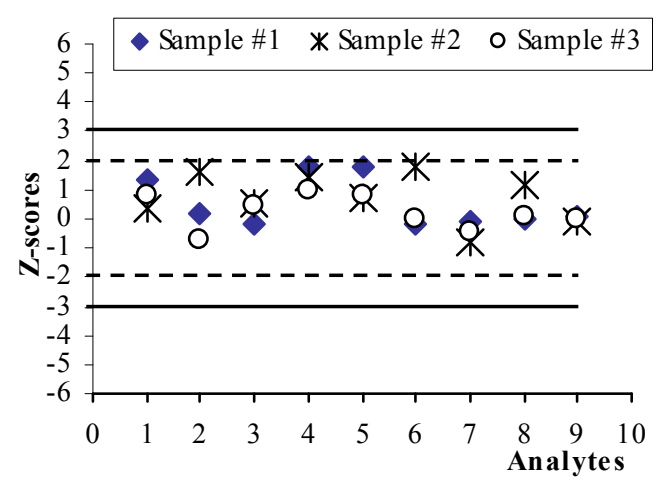

Fig. 3.2.b. Minor and major ions 2008.

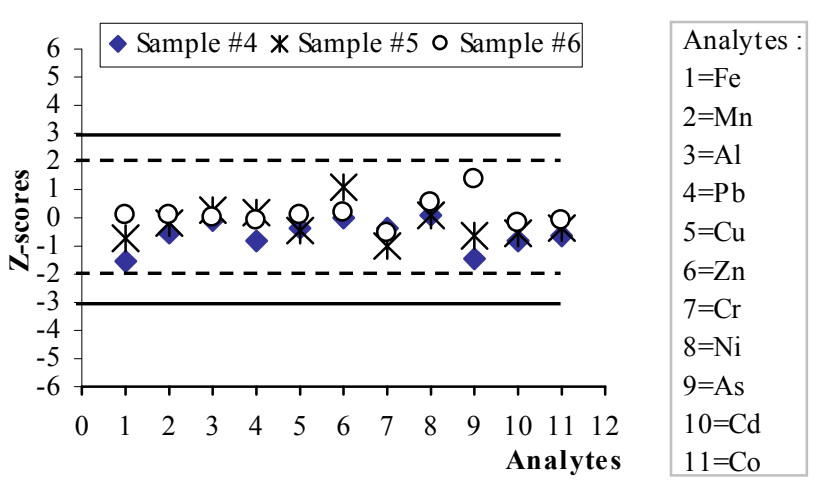

Fig. 3.3.a. Trace metals 2009 .

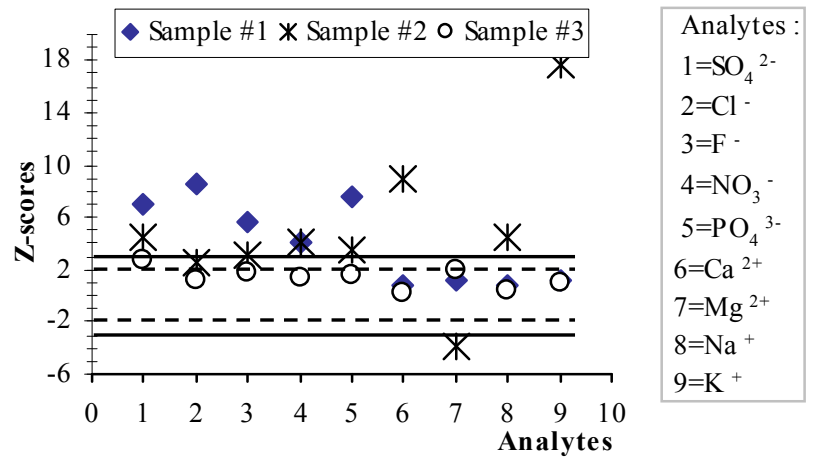

Fig. 3.3.b. Minor and major ions 2009 .

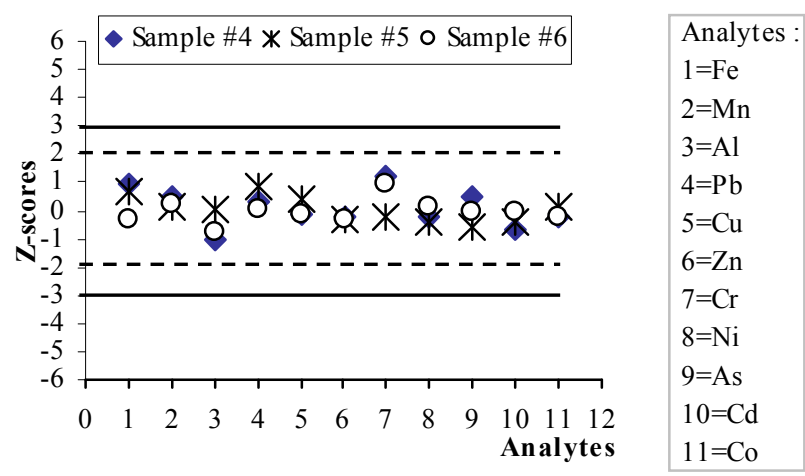

Fig. 3.4.a. Trace metals 2010.

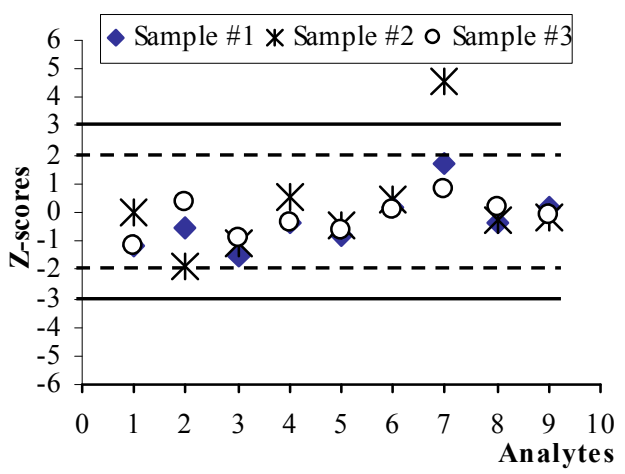

Analytes : $1=\mathrm{SO}_{4}{ }^{2-}$ $2=\mathrm{Cl}$ $3=\mathrm{F}$. $4=\mathrm{NO}_{3}$ $5=\mathrm{PO}_{4}{ }^{3}$ $6=\mathrm{Ca}^{2+}$ $7=\mathrm{Mg}^{2+}$ $8=\mathrm{Na}^{+}$ $9=\mathrm{K}^{+}$

Fig. 3.4.b. Minor and major ions 2010.

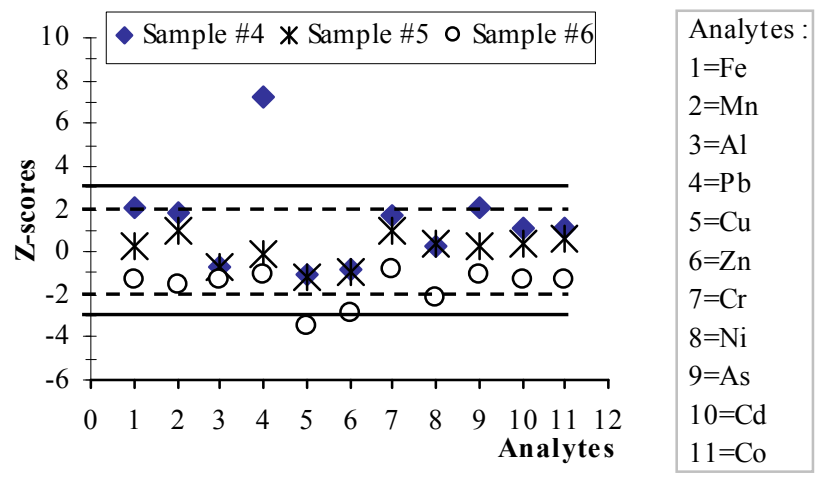

Fig. 3.5.a. Trace metals 2011. 


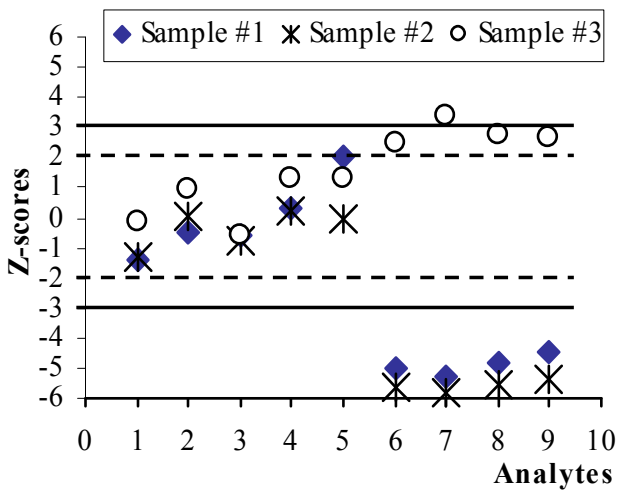

Fig. 3.5.b. Minor and major ions 2011.

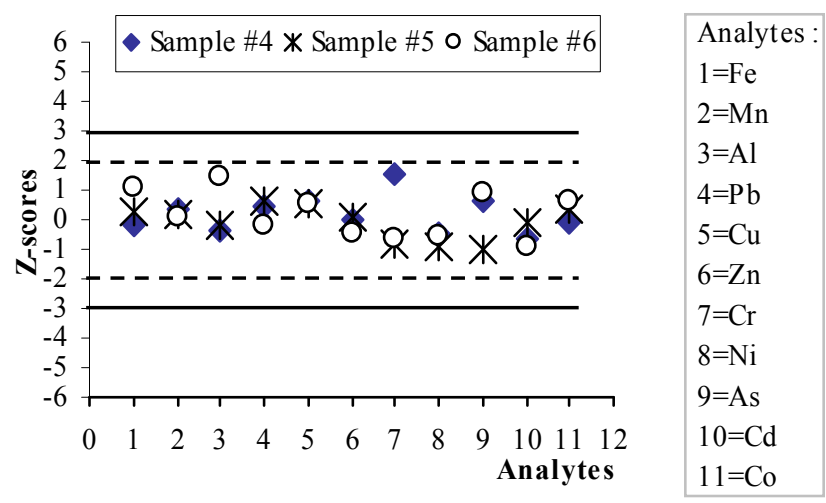

Fig. 3.6.a. Trace metals 2012.

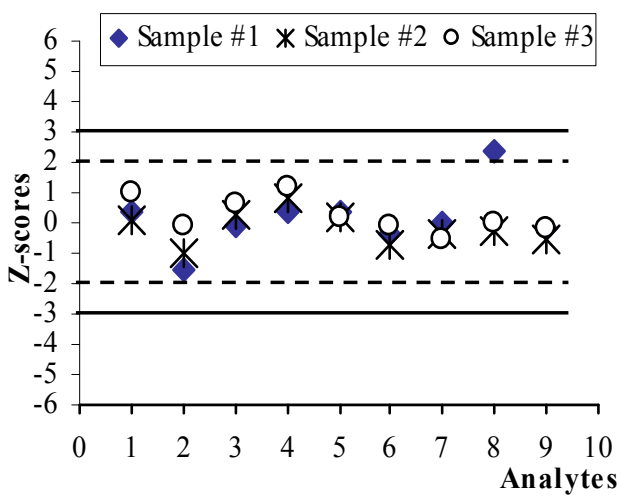

Fig. 3.6.b. Minor and major ions 2012.

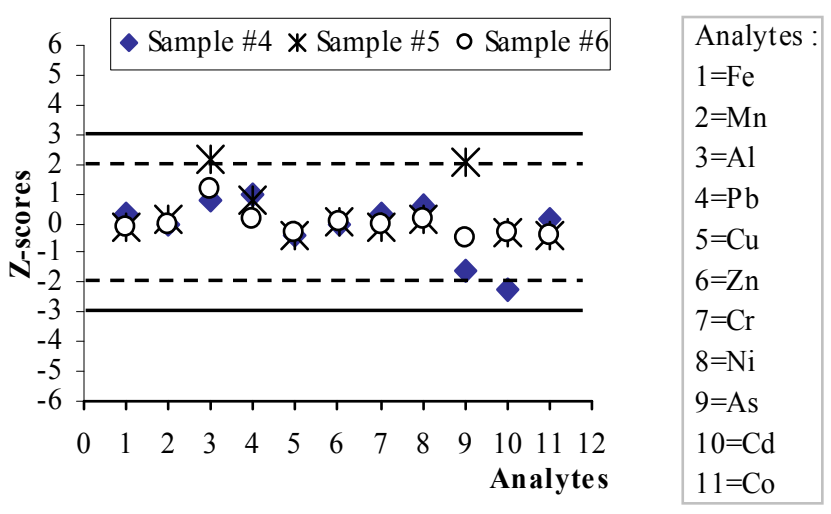

Fig. 3.7.a. Trace metals 2013.

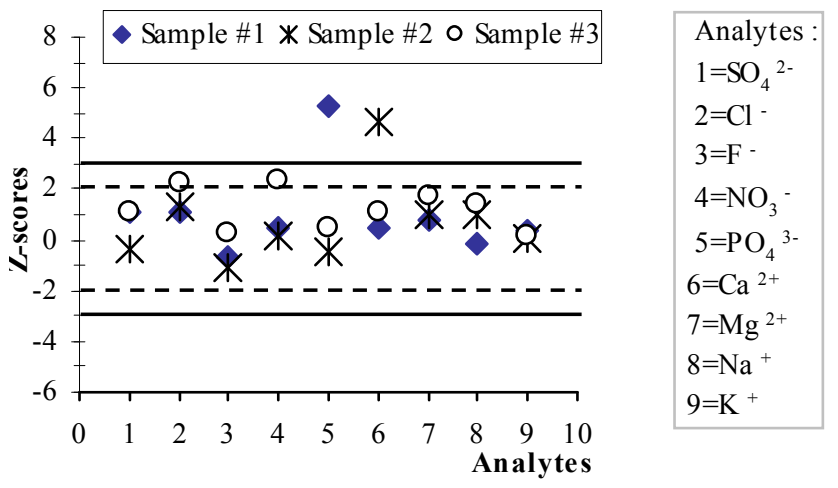

Fig. 3.7.b. Minor and major ions 2013.

To summarize, the evaluation report is displayed graphically in figure 4.

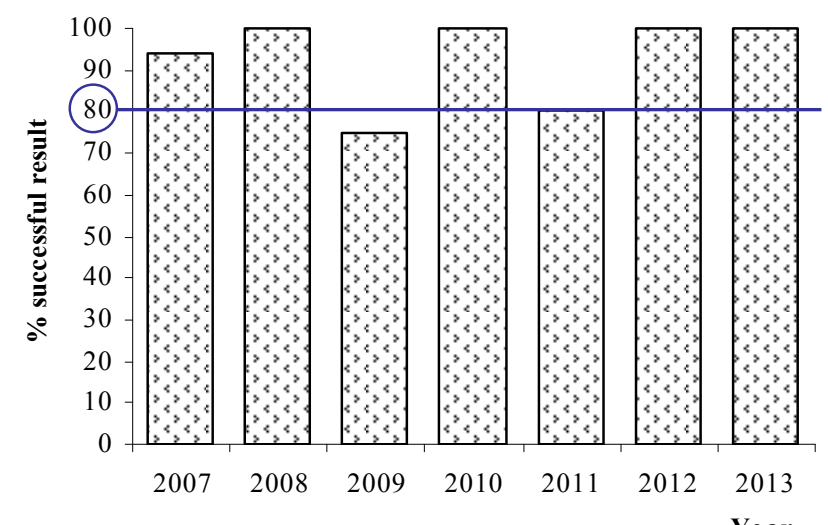

Fig. 4. Percentage of successfully analysed values during the period 2007-2013.

INSTN-Madagascar is succeeded to have more than $80 \%$ of the values within tolerance limits on 2007, 2008, 2010, 2012 and 2013. Anions and cations results undermine the ranking respectively in 2009 and in 2011.

\subsection{Impact Evaluation}

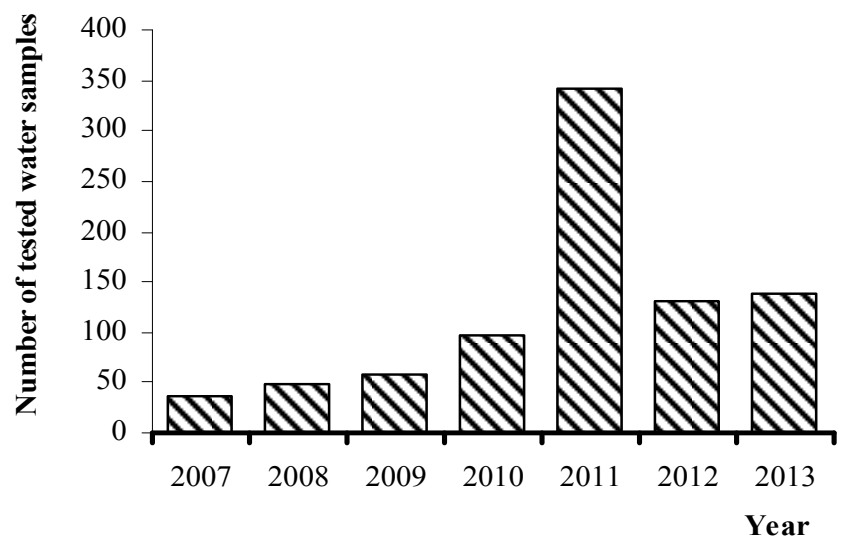

Fig. 5. Number of tested water samples during the period 2007-2013.

Owing to the assistance of the International Atomic Energy Agency through analytical equipments and trainings on the one hand and to the efforts of local testing laboratory on the 
other hand, the clients' needs are met due to the increase of the number of analytes to be measured and their confidence on the reliability of analytical results. Figure 5 shows the increase of the number of water samples that were tested at INSTN-Madagascar during the period 2007 to 2011.

Indeed, a decrease of the demand is observed in 2012. Effectively, due to the expansion of mining industries in Madagascar, the most of them were on phase of exploration in 2011. On one hand, they make investigations to find waters for their needs and on other hand, to check the baseline (in term of water quality) of the site where they are going to be installed. The next two years, the clients' requests go back to normal.

\section{Conclusion}

The need for ongoing confidence in laboratory performance is not only essential for INSTN-Madagascar and its customers but also for other interested parties, such as regulators and laboratory accreditation bodies.

In order to accomplish laboratory accreditation, especially for INSTN-Madagascar, participation in interlaboratory comparison is a required approach to demonstrate the validity of measurement results to customers.

The proficiency testing program by interlaboratory comparison is one of the useful tool in meeting the requirements of ISO/IEC 17025 (clause 5.9) [10] in the area of quality assurance of laboratory results.

It is not about 'passing' or 'failing' a test but it is about participating and learning from the results to avoid that errors recur.

One bad result does not make a laboratory bad. One good result does not make a laboratory supreme. But the objective is the detection of unsuspected sources of errors.

In parallel, the study determines the concentrations of major and minor ions and metals in water samples. The results show that the three analytical methods used in the present PT scheme namely IC, AAS and TXRF are reliable for the measurements of these chemicals.

Extensive studies on the other environmental samples such as drinking water, aerosols, soils, ... have been developed at INSTN-Madagascar [11], [12], [13] and this latter should continue the programme in order to carry out confidently the Environmental Quality Assessment.

\section{Acronymes}

INSTN-Madagascar: Institut National des Sciences et Techniques Nucléaires-Madagascar

TXRF: Total Reflection X-Ray Fluorescence

AAS: Atomic Absorption Spectrometry

IC: Ion Chromatography

SADC: Southern African Development Community

XRFE: X-Ray Fluorescence and Environment

PT: Proficiency Testing

RMs: Reference Materials

SRMs: Standard Reference Materials

CRMs: Certified Reference Materials

\section{IAEA: International Atomic Energy Agency}

\section{Acknowledgments}

The interlaboratory comparison described in this report has been made possible thanks to the work carried out by SADC WaterLab Association.

The authors are grateful to the International Atomic Energy Agency, Vienna Austria, within the frame of RAF/0/027 and MAG/8/007 projects through expert service, supplying of equipment and training of staff.

The authors thank Dr. Ir. Peter Bode - Nuclear Science and Technology, Nuclear Security and Quality Management, Delft University of Technology, The Netherlands - for exchange of ideas and encouragement.

\section{References}

[1] J. S. Fritz, D. T. Gerde, "Ion Chromatography", Weinheim, 4th, Completely revised and enlarged, 2009, pp. 21-35

[2] H. Aiginger "Historical development and principles of total reflection X-ray fluorescence analysis", Spectrochem Acta, v.46B, 1991, p.1313.

[3] R. E. Van Grieken, A. A. Markowicz, "Handbook of X-Ray Spectrometry", Marcel Dekker, New York, v.14, 1993, pp. $453-474$

[4] J.E. Cantle, "Atomic Absorption Spectrometry", Techniques and instrumentation in analytical chemistry, Elsevier, v.5, 1982.

[5] IAEA, "Sampling, Storage and Sample preparation procedures for X Ray Fluorescence analysis of Environmental materials", IAEATECDOC-950, Vienna, 1997, p.32.

[6] C. Galas, "Assessment of trace metal bioavailability in soils and river waters using different analytical techniques to predict metals uptake by biota", Thesis, Università DegliStudi di Roma "TOR VERGATA", 2008, p.19.

[7] Appendix F: "Guidelines for Standard Method Performance Requirements", AOAC Official Methods of Analysis, 2012, p.9, http://www.eoma.aoac.org/app_f.pdf

[8] EURACHEM, "Selection, Use and Interpretation of Proficiency Testing Schemes", 2nd edn, 2011, p.14, http://www.eurachem.org/images/stories/Guides/pdf/Eurache m_PT_Guide_2011.pdf

[9] Ph. Quevauviller, E. A. Maier, "Interlaboratory studies and certified reference materials for environmental analysis", Techniques and instrumentation in analytical chemistry v.22, Elsevier, 1999, p.501.

[10] EN ISO/IEC 17025, "General requirements for the competence of testing and calibration laboratories", CEN/CENELEC, Brussels, 2005, p.20.

[11] M. Rasolofonirina, L. V. Randriamanivo, M. T. Andrianarilala, Raoelina Andriambololona, "Trace Elements and Physico-chemical Quality of the Well Waters in Mahitsy, Province of Antananarivo, Madagascar", HEPMAD 04, eConf SLAC-Stanford Univ., 2004. 
[12] Raoelina Andriambololona, N. N. Andriamahenina, L. V. Rakotozafy, "Qualité des eaux de boisson locales et importées vendues en bouteille à Madagascar", Académie Nationale des Arts, des Lettres et des Sciences, Antananarivo, 2009.

[13] H. Rakotondramanana, L. V. Randriamanivo, Raoelina
Andriambololona, M. Rasolofonirina, "Application de la Fluorescence-X à réflexion totale à l'étude des matières particulaire et des métaux lourds de la pollution de l'air dans la ville d'Antananarivo, Madagascar", Rev. Pollution Atmosphérique, v.178, 2003, pp.273-283. 